\title{
Hypoxemia indicative of Rendu Osler disease during SARS Cov-2 pandemic
}

Herveat RAMANANDAFY ${ }^{1}$, Princy Parfait Andriamahenina ${ }^{1}$, Harison Michel Tiaray ${ }^{1}$, Anjara Mihaja Nandimbiniaina ${ }^{1}$, Angela Zamelina Razafindrasoa ${ }^{1}$, Sonia Marcelle Razafimpihanina ${ }^{1}$, Diamondra ombanjanahary Andriarimanga ${ }^{1}$, Solohery Jean Noel Ratsimbazafy ${ }^{1}$, Jocelyn Robert Rakotomizao ${ }^{1}$, Joëlson Lovaniaina Rakotoson ${ }^{1}$, and Hanta Marie Danielle Vololontiana ${ }^{2}$

${ }^{1}$ University of Madagascar

${ }^{2}$ University of Antananarivo Faculty of Medicine

November 10, 2021

\section{Abstract}

Rendu Osler's disease is a genetic disease characterized by mucocutaneous and visceral telangiectasias. Rendu Osler's disease was discovered during hypoxemia during an outbreak of SARS-Cov2.This was a 36-year-old woman with exertional dyspnea and severe hypoxemia revealing pulmonary arteriovenous malformations on chest CT scan.

\section{Hosted file}

manuscrit revised.docx available at https://authorea.com/users/445462/articles/544974hypoxemia-indicative-of-rendu-osler-disease-during-sars-cov-2-pandemic

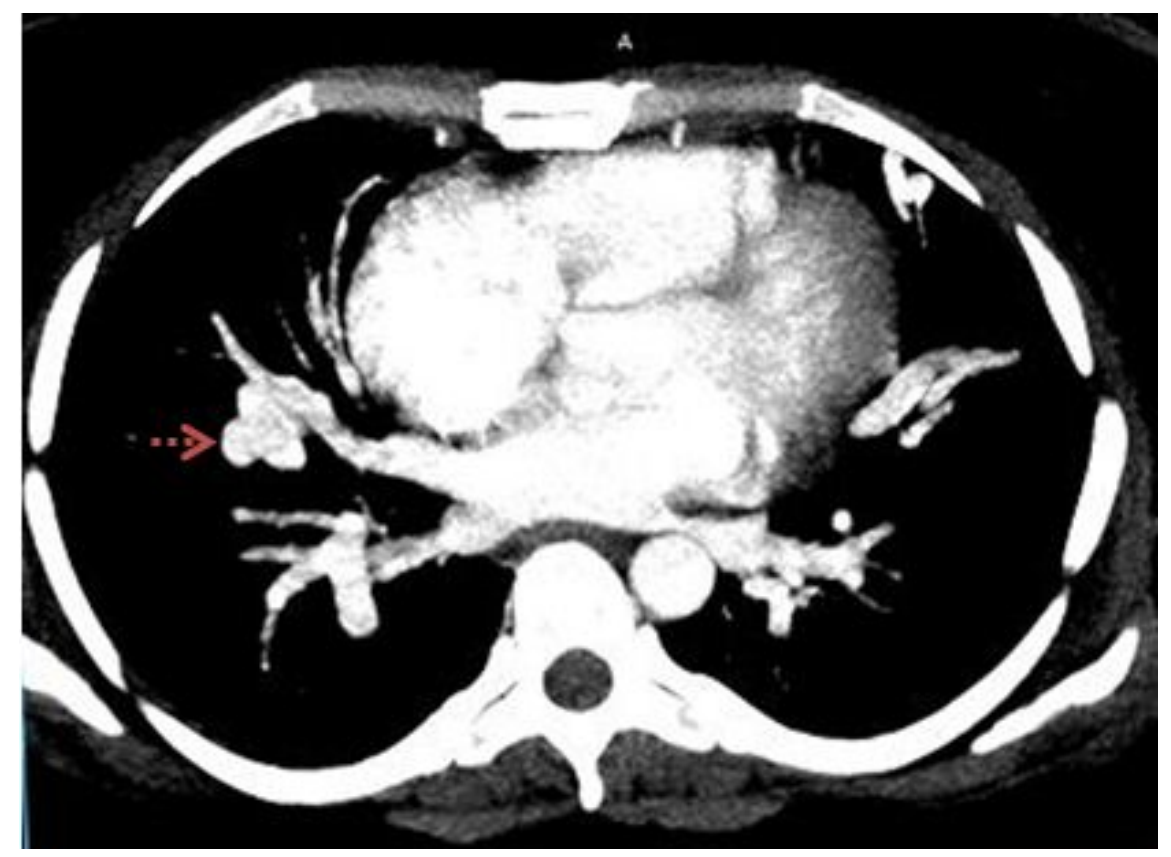




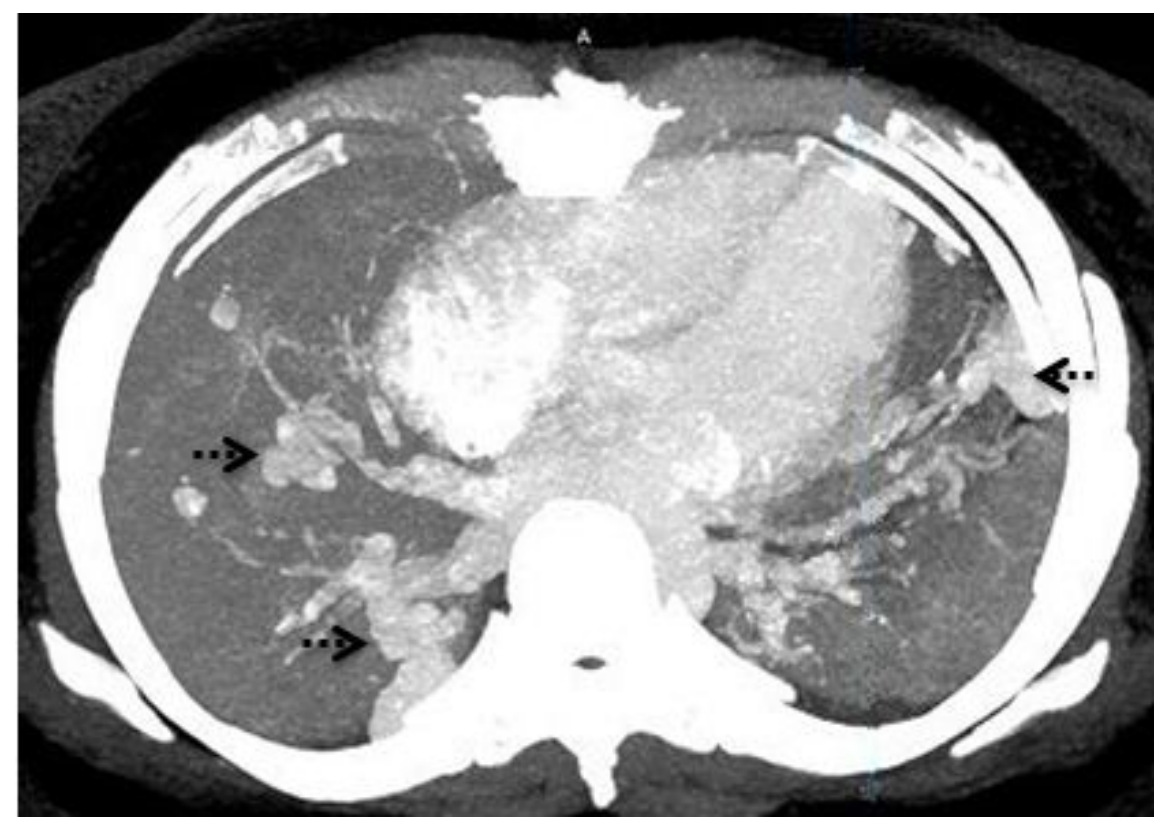

